\title{
$O$ efeito do império da beleza em um grupo de alunos da educação infantil: reflexões acerca da discriminação etária
}

The effect of the beauty empire on a group of kindergarten students: reflections on age discrimination

El efecto del imperio de la belleza en un grupo de estudiantes de jardín de infancia: reflexiones sobre la discriminación por edad

Wânia Marlene Lopez Russo ORCID: https://orcid.org/0000-0002-4739-1147 Rede Municipal de Ensino de Porto Alegre, Brasil

E-mail: w.russos2312@gmail.com

Fernando Icaro Jorge Cunha

ORCID: https://orcid.org/0000-0002-0064-4039

Universidade Federal do Pampa, Brasil E-mail: icaro729@gmail.com

Suelen Martini Azambuja ORCID: https://orcid.org/0000-0002-0232-6456 Secretaria de Educação do Estado de Santa Catarina, Brasil

E-mail: suelenmartini@unochapeco.edu.br

Ricardo Santos de Almeida

ORCID: https://orcid.org/0000-0003-1266-2557

Universidade Federal de Santa Maria, Brasil

E-mail: ricardosantosal@gmail.com

Daiane Maira Soccal

ORCID: https://orcid.org/0000-0002-3217-4326

Universidade Federal de Santa Maria, Brasil

E-mail: daia.soccal@gmail.com

Adriana da Silva Biavaschi

ORCID: https://orcid.org/0000-0003-3521-4378 Universidade Federal do Pampa, Brasil

E-mail: fereadri2002@gmail.com

Márcio da Mota Machado Filho

ORCID: https://orcid.org/0000-0002-3443-2931

Universidade Federal de Santa Maria, Brasil

E-mail: marciotm95@gmail.com

Janete Hickmann

ORCID: https://orcid.org/0000-0001-6318-2065 Universidade Feevale, Brasil

E-mail: janete22h@gmail.com

Salete Pereira Zanella

ORCID: https://orcid.org/0000-0002-9135-2698 Universidade Federal de Pelotas, Brasil E-mail: soldreher@gmail.com

Marlise Grecco de Souza Silveira ORCID: https://orcid.org/0000-0003-4612-9128 $10^{\circ}$ Coordenadoria Regional de Educação, Brasil

E-mail: marlisegreccos@gmail.com

Joana Maristela Moreira Moleda

ORCID: https://orcid.org/0000-0003-1538-7749 Rede de Ensino Municipal e Estadual de Uruguaiana, Brasil E-mail: moleda.jo@gmail.com

Leni Vieira Dornelles

ORCID: https://orcid.org/0000-0001-7130-9513 Universidade Federal do Rio Grande do Sul, Brasil

E-mail: ivdornelles@yahoo.com.br

\section{Resumo}

Este trabalho tem por objetivo analisar lançando um olhar problematizador sobre as questões que têm marcado a atuação de uma professora junto a uma turma de Jardim II, partindo das narrativas de seus alunos da Educação 
Infantil, seus sentimentos e ações que se fazem presentes frequentemente e que caracterizam os conceitos que os mesmos apresentam sobre a relação entre ser professora e ser jovem e a negação em aceitar como professores pessoas que não se enquadram dentro dos conceitos de beleza e juventude por eles estabelecidos. Esses questionamentos propeliram a necessidade de investigar e analisar com acuidade as questões pessoais e familiares que regem o comportamento dessas crianças, utilizando como referencial de pesquisa os estudos que se caracterizam como pós-estruturalistas, em especial os estudos de Foucault. Esta discriminação etária apresentada pelos educandos, propiciou resultados demasiados que englobam a subjetividade, bem como, o efeito do império da beleza.

Palavras-chave: Juvenescimento; Beleza; Discriminação.

\begin{abstract}
This work aims to analyze, casting a problematic look at the issues that have marked the performance of a teacher with a kindergarten II class, starting from the narratives of her students, their feelings and actions that are frequently present and that characterize the concepts they present about the relationship between being a teacher and being young and the refusal to accept as teachers people who do not fit within the concepts of beauty and youth established by them. These questions propelled the need to investigate and accurately analyze the personal and family issues that govern the behavior of these children, using studies that are characterized as post-structuralist as a research reference, especially the studies by Foucault. This age discrimination presented by the students, provided too many results that encompass subjectivity, as well as the effect of the beauty empire.
\end{abstract}

Keywords: Youth; Beauty; Discrimination.

\title{
Resumen
}

Este trabajo tiene como objetivo analizar, lanzando una mirada problemática a los temas que han marcado el desempeño de una maestra con una clase de kindergarten II, a partir de las narrativas de sus alumnos, sus sentimientos y acciones que están frecuentemente presentes y que caracterizan los conceptos que presente sobre la relación entre ser docente y ser joven y la negativa a aceptar como docentes a personas que no encajan dentro de los conceptos de belleza y juventud establecidos por ellos. Estas preguntas impulsaron la necesidad de investigar y analizar con precisión las cuestiones personales y familiares que rigen el comportamiento de estos niños, utilizando como referencia de investigación estudios que se caracterizan como postestructuralistas, especialmente los estudios de Foucault. Esta discriminación por edad presentada por los estudiantes, arrojó demasiados resultados que abarcan tanto la subjetividad como el efecto del imperio de la belleza.

Palabras clave: Juventud; Belleza; Discriminación.

\section{Introdução}

Ao pensar em um tema instigante para desenvolver o Trabalho de Conclusão do Curso de Especialização, busquei inspiração em minhas experiências como educadora de turmas de Educação Infantil, em especial do jardim II, turma em que atuo neste ano.

Desde a graduação, quando realizei os estágios curriculares, deparei-me com uma realidade que se mostrava presente em várias turmas de educação infantil, de estabelecimentos de ensino públicos e privados em várias faixas etárias, uma preocupação excessiva por parte das crianças em não crescer. O medo de se tornar adulto e envelhecer se fazia presente através de gestos, ações e falas das crianças, seja nas atividades de roda de conversas, conto, seja em brincadeiras como nas conversas informais.

A resistência ao crescimento acabou sendo o foco do meu estágio do sétimo semestre, quando trabalhei com uma turma de maternal I, em uma escola particular que atendia crianças de classe média. Era comum nesta turma comentários como: "Vou ficar em baixo da mesa para não crescer", ou "Profe não quero comer, assim vou ser sempre pequeno".

Neste trabalho abordei a preocupação que meus alunos apresentavam em crescer, as tentativas que faziam para retardar o crescimento, bem como, o trabalho que realizei com a turma para que aceitassem o crescimento como algo normal e positivo, com o relatório intitulado "As novas aventuras do menino que não queria crescer", onde fui narrando as experiências vividas e os trabalhos realizados em sala de aula.

De certa forma, não me surpreendeu a presença do medo de envelhecer dos alunos desta turma, nem foi difícil trabalhar com eles, pois, como mãe já havia me defrontado com esta etapa de vida de duas filhas e também de sobrinhos, com quem convivi. 
Surpresa foi o que encontrei quando, há alguns meses, assumi uma turma de jardim II, com alunos entre 5 (cinco) a 6 (seis) anos, em uma escola de Educação Infantil de Porto Alegre, que atende um público de classe média alta. Já no primeiro contato com meus novos alunos encontrei novamente a sombra do medo de crescer e em especial de envelhecer, só que desta vez aliado a certo desdém a tudo aquilo que difere do jovem e do belo, ou, em outras palavras, o considerado "velho".

As crianças desta turma demonstravam uma valorização excessiva da beleza e juventude a ponto de discriminarem todas as pessoas que de alguma forma não se "emoldurassem" nos modelos de professora instituídos por eles como naturais.

Ao ser apresentada à turma tive como boas vindas comentários como: "Tu não é profe, Teu nome é de vó e tu tem rugas. Parece vó! Preferimos a profe da outra turma, ela é loira, nova e bonita! Só gostamos de quem tem menos de dezenove anos!, "Tu és muito velha, não podes trabalhar com criança!". Esta narrativa das crianças fomentou o meu Trabalho de Conclusão do Curso e partindo dela desejo debruçar-me e realizar minhas reflexões e problematizações.

Ao receber estes comentários como boas vindas busquei rapidamente respostas aos mesmos explicando à turma que respeitava suas opiniões e propus que nós nos conhecêssemos melhor. Eles retornaram dizendo que não queriam me conhecer, pois, por eu ser uma velha, nada poderia acrescentar a eles. Propus a eles que ficássemos juntos durante uma semana para que pudessem me conhecer e se ao final deste tempo, se não me aceitassem, chamaríamos a coordenadora pedagógica para que juntos encontrássemos uma solução.

Toda expectativa que eu tinha de ser aceita como professora se desvaneceu com esta recepção. A coordenadora se afastou e eu permaneci na sala com os alunos que me olhavam e cochichavam baixinho. Apesar dos sentimentos de rejeição que sofri por parte de meus novos alunos neste momento, procurei ouvi-los sobre seus sentimentos em relação a minha chegada. Sentei-me com eles e pedi que falassem como deveria ser uma professora para eles. Eles disseram o que pensavam sobre a idade e características físicas que acreditavam ser necessárias às professoras, o que me faz lembrar de Felipe (2004, p. 4 apud Ramos 2006, p. 23), quando afirma que: "As culturas infantis devem ser conhecidas a partir do que as próprias crianças dizem, pensam, sentem e fazem”. Problematizando as vozes dessas crianças que se levantaram para dizer o que pensavam, queriam e sentiam, questionei o quanto suas vozes têm sido abafadas, pois, "pouco se ouve e pergunta às crianças" (Quinteiro, 2002, p. 21 apud Ramos, 2006, p. 23).

Passado o susto inicial busquei refletir sobre a opinião que estas crianças estavam expressando, que foi construída a partir de relações sociais e culturais que entrelaçadas resultaram nestes conceitos que, provavelmente, não foram construídos por elas e talvez nem expressassem seus verdadeiros sentimentos. Concordo com Steinberg e Kincheloe (2001) quando dizem que a infância também é um artefato social e histórico, constituída "por questões sociais, culturais, políticas e econômicas que atuam sobre ela" (Steinberg \& Kincheloe, 2011, p. 11). Ou seja, a criança é produzida na interação com o mundo e por isso torna-se um sujeito educado de um jeito e não de outro. Estas crianças provavelmente estavam verbalizando conceitos culturais e sociais que haviam assimilado através de suas relações e interações com a realidade cultural e social a que pertencem.

Vivemos hoje, numa sociedade dominada pelo interesse, pelo lucro, ao mesmo tempo, pela insegurança e pelo medo. Uma sociedade manipulada por interesses políticos, econômicos, sociais e religiosos sem precedentes. Na realidade, vivemos em um mundo cada vez mais globalizado, onde todos nós somos vítimas inocentes dos ataques terroristas e prisioneiros das loucuras alheias. Somos todos vitimas do terrorismo como também de suas represálias. 4 Ao mesmo tempo, somos testemunhas históricas das enormes carências do ser humano, não apenas em termos de conhecimento e educação, mas também de afetividade, amor, solidariedade e espiritualidade (Moraes, 2000, p. 3-4).

A partir deste primeiro contato venho buscando, através de minhas ações, desconstruir estes conceitos com a turma. Minha atuação junto a essa turma não se mostra "cor de rosa", pois, apesar de demonstrarem na maior parte do tempo, que me aceitam como sua professora, meus alunos aproveitam todas as oportunidades para me lembrar que sou velha, que não sou a 
professora idealizada pela turma, e que, segundo eles, apesar de eu ser legal, carrego comigo a marca da idade que me descaracteriza como professora de Educação Infantil.

Portanto, a idade é uma categoria ideologizada que carrega vários estereótipos. Os estereótipos são percepções automáticas, socialmente partilhadas e têm origem na interação social e estão na base de atitudes de discriminação social que ficam armazenados na memória coletiva, influenciando as percepções e os comportamentos em relação ao grupo e aos seus membros (Carvalho, 2020, p. 7).

Ao longo dos meses em que tenho atuado como professora desta turma, jamais fui recepcionada com beijos ou cartinhas, como é de praxe nas turmas de jardim. Ao contrário, às vezes enquanto eu conto uma história ou explico alguma atividade os meninos colocam as duas mãos no rosto enrugando-o e riem. Nesses momentos as meninas falam da professora que tiveram no ano anterior dizendo: "Ah, profe! Tu tinha que conhecer a Pati ela era linda. Uma pele. ruguinha".

Estas questões têm marcado a minha atuação junto a essa turma, e me estimularam a lançar um olhar mais problematizador frente às narrativas de meus alunos, ou seja, refletir sentimentos e ações que se fazem presentes frequentemente entre este grupo de alunos, tais como: Qual a emergência do conceito de beleza? Quais as condições de possibilidade para que estas falas e ações perpassem a vida das crianças? Estes conceitos parecem, por vezes, não fazerem parte do universo infantil, mas apesar disso estão presentes em falas, gestos e ações. Qual o efeito da beleza e juvenescimento na vida destas crianças para que se mostrem tão exigentes com a aparência física dos adultos? Em especial das professoras e demais profissionais que atuam na escola. Esses questionamentos me impulsionaram a analisar com acuidade as questões pessoais e familiares que regem o comportamento dessas crianças, utilizando como referencial de pesquisa os estudos que se caracterizam como pós-estruturalistas.

Ao lançar um olhar mais investigativo sobre este grupo de alunos, fui aos poucos dando-me conta que talvez seja esta a realidade enfrentada por muitas das professoras e professores que não se enquadram nos conceitos de beleza e juventude dos alunos desta turma, pois outros profissionais que atuam junto a eles já enfrentaram ou enfrentam as mesmas dificuldades com que tenho me deparado no convívio com esses alunos. Em outras palavras, estes profissionais não são aceitos nem respeitados por eles. Aos professores são atribuídos apelidos depreciativos e os alunos negam-se a participar das atividades que estes desenvolvem junto a esta turma.

A título de exemplo, o caso do o professor de informática, negro usando cabelo rastafari, que foi rotulado por meus alunos de vagabundo e xingado com palavrões ao não permitir que dois meninos entrassem em luta corporal em uma de suas aulas. Ou com a professora de música que por ser, segundo eles, feia e velha é apelidada de vagabunda e de bruxa. O efeito dessas narrativas foi o pedido de demissão do professor, que preferiu sair da escola e o afastamento do aluno que colocou o apelido na professora. Os pais da criança argumentaram que retiraram o filho da aula de música por atribuírem à professora a falta de manejo, pois o menino queixava-se que a professora brigava com ele.

Pensei sobre as diferenças existentes entre turmas de uma mesma faixa etária, pois meu estágio do oitavo semestre da graduação do curso de pedagogia foi realizado em uma turma de jardim B, em uma Escola Estadual situada na periferia de Porto Alegre, com crianças com faixa etária entre cinco e seis anos. Ao contrário de minha turma atual, para aquela turma, as questões de beleza e juventude pareciam pouco importantes, já que todos se mostravam receptivos a todas as professoras que atuavam junto à turma. Percebe-se que a sociedade e a cultura disciplinam o sujeito, e estas crianças que são herdeiras desta sociedade, assistem o assujeitamento e disciplinamento de corpos. Fischer (1994) afirma que para Foucault as disciplinas são "métodos que permitem o controle minucioso das operações do corpo, que realizam a sujeição constante de suas forças e lhes impõem uma relação de docilidade-utilidade" (Fischer, 1994, p 52). 


\section{Metodologia}

O presente estudo possui natureza qualitativa, delineado a partir de um estudo de caso. De acordo com Martins (2004), pesquisas qualitativas visam a sistematização dos resultados observados através de valores, comportamentos, experiências, habilidades, competências e particularidades, sem a necessidade de quantificá-los. Segundo Severino (2013), estudos de caso proporcionam um desígnio direcional e peculiar, onde a coleta de dados é semelhante a uma pesquisa de campo, agregando os aspectos qualitativos. Ainda assim, o autor sugere que:

O caso escolhido para a pesquisa deve ser significativo e bem representativo, de modo a ser apto a fundamentar uma generalização para situações análogas, autorizando inferências. Os dados devem ser coletados e registrados com o necessário rigor e seguindo todos os procedimentos da pesquisa de campo. Devem ser trabalhados, mediante análise rigorosa, e apresentados em relatórios qualificados (Severino, 2013, p. 105).

Como instrumento de coleta de dados, considerando os mesmos terem sido obtidos através de vivências condicionadas à rotina escolar da professora, foi utilizado o diário de bordo, onde os discursos foram transcritos e organizados sistematicamente. O diário de bordo se torna um excelente aliado nesse tipo de pesquisa, uma vez que proporciona a organização de múltiplas perspectivas de narrativas observadas através de aspectos empíricos, aspectos reflexivos, interesses, motivações, planejamentos e experiências (Guerra, 2020), (Wendling \& Campos, 2013).

Para a análise de dados, utilizamos a metodologia de análise de conteúdo que agrega "um conjunto de técnicas de análise das comunicações. Trata-se de se compreender criticamente o sentido manifesto ou oculto das comunicações" (Severino, 2013, p. 106). Este método enquadra-se na perspectiva deste trabalho, pois são sistematizadas informações do diário de bordo, através do produto de interação e comunicação com os alunos, somando valores e experiências pessoais, bem como, um contexto que é fundamentado historicamente (Pereira et al, 2018).

O método utilizado possibilitou a problematização sobre os discursos observados, assim como a reflexão crítica dos resultados, relacionando com a bibliografia pertinente, buscando discutir sobre a necessidade evidenciada nos estudantes de um estilo padrão de estereótipo em professoras, sendo o ideal “jovens e belas” (aos olhos da sociedade contemporânea).

\section{Resultados e Discussão}

\subsection{E por falar em beleza}

Nós, enquanto seres humanos possuímos um corpo que, desde a concepção envelhece e sofre transformações. Talvez pela dificuldade que sentimos em conviver com a perspectiva da morte é que acreditamos que o envelhecimento produz relação com o fim de tudo. A modernidade em sua perspectiva de categorização dos sujeitos acabou delimitando o tempo vivido subdividindo-o em idades, gerações e fases de vida. Infância, adolescência, fase adulta, madureza e velhice são demarcações trazidas pela modernidade. Entendo que estas categorizações transcendem a idade cronológica de cada indivíduo, ou mesmo dos corpos que envelhecem, daí as narrativas das crianças em não aceitar o corpo visto como velho, como um corpo que não é aceito para atuar junto a elas.

Segundo Faux (2000), nossa sociedade faz um constante investimento simbólico e cultural no corpo que envelhece. Não temos determinada idade, pertencemos à idade que temos ou aparentamos ter. A cada idade somos interpelados a adotar certos tipos de comportamentos, marcas sociais, sentimentos, modos de ser e estar compatíveis com o grupo etário a que pertencemos. Para meus alunos, por eu ser considerada velha, - fico engraçada quando brinco, - não posso usar determinadas roupas, por serem roupas para mulheres jovens usarem. Ou se canto, as meninas dizem: “Profe, não canta, tua voz é de velha! Velha não pode cantar!'”. 
De algum modo, parece não haver neutralidade nessas narrativas. A idade passa a definir e descrever o indivíduo. Também desempenha um papel de controle das relações sociais, pois define vários papéis sociais, como o ingresso no mercado de trabalho, maioridade legal, aposentadoria. De acordo com a idade do sujeito a sociedade cobra o que ele pode ou não fazer, experimentar, viver ou não. Desse modo, talvez seja este o efeito destes discursos em nossa sociedade atual que falam da importância do juvenescimento, "obrigando" os sujeitos a negar cada vez mais os sinais de envelhecimento. Mais e mais os sujeitos tendem a não participar das atividades comuns em outros tempos a sua faixa etária "tendo que adotar" comportamentos, vestuário, processos cirúrgicos que retardam os sinais de envelhecimento, como se o envelhecer caracterizasse uma anormalidade, diante da sociedade do século XX que aceita como normal a juventude.

Observa-se, mesmo que rapidamente, olhando para a história da beleza, que o desejo da beleza aliada à eterna juventude foi perseguido, em especial por mulheres de todas as culturas e épocas, ao longo da história humana. O conceito de beleza tem se transformado ao longo dos séculos conforme as tendências culturais, sociais ou os modelos vigentes em determinado tempo e espaço. Assim, "em todos os tempos, a moda impôs seu estilo de beleza e vice-versa" Faux (2000 p.14). Essas transformações são marcadas por variações entre maquiagens, tipo de corpo, porém um ponto sempre se faz presente nestes conceitos, o da juventude ou do juvenescimento.

Na Antiguidade, por meio de rastros deixados por deusas, faraós, sacerdotisas, rainhas e escravas, o Oriente antigo nos fala de beleza com uma simplicidade que toca nossa modernidade para além dos milênios. Banhos, máscaras de lama do Nilo, massagens com óleos, máscaras, maquiagens eram utilizadas pelas classes nobres. Embora os escravos não utilizassem dos mesmos artifícios para enaltecer a beleza, costumavam pintar os olhos como ação simbólica para tornarem-se mais belos.

$\mathrm{Na}$ Grécia, a beleza na época de Ulisses e Helena era, acima de tudo, a harmonia das proporções. Usava-se alvaiade de chumbo colocando-o no rosto para que parecesse mais branco, sombreavam-se os olhos com kajal ou até fuligem. Na Idade Média, toda imagem de mulher se divide entre Maria e Eva, uma considerada santa e outra demoníaca. A pureza (sem retoques das imagens) de Maria, mãe daquele que redimiu os pecados de uma humanidade, foi corrompida pela primeira mulher, que a imaculou através de artifícios como a personificação do mal.

É um momento onde o rosto individual não existe, o espelho era fustigado, por ser considerado "a porta do inferno". A maquiagem era considerada diabólica, pois enganadora era a beleza que mascara a natureza culpada das mulheres. "A heroína que conquista os corações dos cavaleiros tem a pele branca como o lírio, leite ou espinheiro alvar, ainda adolescente ou muito jovem" Faux (2000 p. 42). Já naquela época, o conceito de beleza era associado à tez branca, ao cabelo loiro ou ruivo e à juventude e à pureza.

No Renascimento, Vênus rompe o círculo de modelo de perfeição entre Eva e Maria que aprisionava a visão da beleza feminina e a liberdade de celebrá-la. O corpo neste período era considerado a nuvem e a sombra da alma e, por isso, a beleza do corpo volta a ser cultuada. A plástica da mulher é sistematizada por Agnolo Firenzuola, autor do Tratado da beleza das damas, conceituando-a como uma "concórdia bem ordenada" ilustrando sua idéia com um desenho que inscreve o homem num quadrado e a mulher num círculo cujo centro é o sexo. Em toda a Europa, palácios e castelos passam a ser lugares de prazer e de orgulho. $\mathrm{O}$ amor à beleza física invade tudo, "linhas elásticas, graça da juventude, rostos puros, expressões alegres e pudicas, cabelos louros flutuando sobre os ombros [...]" (Faux, 2000. p. 51).

\subsection{Elucidando o contexto histórico}

A Reforma e a contra-reforma foram períodos onde toda a exuberância do Renascimento foi combatida. A beleza passa a ser majestosa, digna, solene, a cabeleira desaparece num coque baixo, o negro é a cor de todas as mulheres e a pérola é a única jóia tolerada. A magreza está em alta. As mulheres francesas levantaram-se e defenderam a liberdade de espírito. 
Protegiam sua pele para que "a neve do rosto não derretesse". O espelho transformou-se em "conselheiro das graças" e estava sempre à mão para que as pintas de tafetá escuro pudessem ser feitas em seus rostos.

No Século XVIII o ruge substitui o natural. Colocado em uma camada espessa até para dormir. Na Grã-Bretanha foi votada uma Lei que penalizava com as mesmas sanções que o crime de feitiçaria a sedução obtida pelo uso de cosméticos, perfumes, dentes e cabelos artificiais. A beleza teve tempo de voltar a ser humana. Ainda neste século, os corpos roliços, rostos doces e delicados de nariz curto, lábios redondos e queixo pontudo, olhos negros e vivos, tez de porcelana; a beleza é tão somente sonhadora, alegre, viçosa. Para ser bela não era preciso ter traços regulares e sim, uma vivacidade de corpo e espírito, uma alegria ágil, um ar "gracioso e picante".

Durante o Romantismo as mulheres cobrem o rosto com preparados tingidos de açafrão ou de tinta azul, bebem vinagre ou engolem montes de limão, jejuam a ponto de desmaiar para que possam alcançar a aparência espectral das tísicas agonizantes. Tudo isso para se aproximarem do conceito de beleza da época. Sobre isto Faux (2000) nos fala: "Um rosto esculpido em mármore, marcado por um seio fatal, uma palidez esverdeada e lívida que transparece sob os véus negros" (Faux, 2000, p.66.).

No Século XIX o conceito de beleza passa a ser o da mulher bem nutrida. As costas gordas, os ombros caídos, os braços cheios de celulite, o seio generoso da mulher honesta e mãe de família. A maquiagem foi praticamente abolida, com exceção do pó branco. Os cremes em série também eram rejeitados, ao invés deles eram utilizadas máscaras caseiras de clara de ovos ou fatias de carne bovina para retardar o envelhecimento.

Apesar da aparência altamente manipulada para sugerir uma juventude impossível, meticulosamente maquiados, embora já visivelmente envelhecidos, eles tentam vender o embuste mercadológico da retenção da passagem do tempo. Pastiche da condição juvenil em estagnação e índice, talvez, da perda do direito de ser velho na obtusa e implacável racionalidade mercantil que caracteriza a atualidade (Castro, 2016, p. 84).

A partir do Século XX a beleza das mulheres, sua maneira de seduzir e a arte de se valorizar evoluíram na mesma cadência. A pele sempre branca, o ruge utilizado em segredo, um traço fino de lápis azul sobre as veias próximas aos olhos eram a moda em 1900. A mulher deveria ser esbelta e elegante, sua cintura deveria medir 42 centímetros que eram conseguidos com espartilhos e pelas cirurgias de retirada de costelas.

Neste período os banhos não eram comuns na Europa, daí os cabelos serem penteados com pente umedecido em óleo perfumado. Em torno de 1909 surgem os primeiros cremes de Elizabeth Arden e Helena Rubinstein. Aparece também o xampu, o secador de cabelos e a primeira coloração capilar de síntese da qual derivam todas as tinturas modernas. Também o esmalte de unhas surge neste ano.

Nos anos 1900 a mulher turca surge como modelo de beleza, as belas mulheres do deserto devem ser sensuais e tórridas, inspiraram a imagem da "vamp" (diminutivo de vampira). O rosto deveria ter uma máscara branca empoada, a boca pequena e as pálpebras levemente sombreadas com muitos cílios postiços (Faux, 2000 p. 94).

O espartilho foi sendo substituído pela cinta elástica. Por esta época (primeira década de 1900) a cirurgia estética teve seu início promissor. Além da técnica utilizada desde 1886, que se caracterizava em descascar a pele (esfoliação), uma nova técnica surge, que consistia em injetar parafina para inchar as bochechas e as pálpebras. Após o final da primeira guerra iniciam-se as cirurgias de correção de nariz, queixo proeminente e a eliminação de rugas. A maquiagem passa a ter como objetivo dar um tom mais rosado à pele, como símbolo de boa saúde.

A partir do ingresso de produtos de beleza em estojos portáteis, com pó, batom, ruge, as mulheres elegantes que viajavam tinham a seu alcance a maquiagem intensificando a necessidade da manutenção da beleza, porém com o advento da Guerra, a Belle Époque teve fim definitivamente. As mulheres foram obrigadas a assumir o controle da vida cotidiana, familiar 
e econômica. Foram impelidas a atuar em todas as profissões, a liberdade de movimentos e o conforto era essencial. Nesta época o espartilho foi abolido, as saias encurtaram e ficaram mais largas para facilitar os movimentos.

Os costumes e o conceito de beleza foram totalmente modificados neste período de Guerra, cabelos curtos, vários perfumes surgiram levando como nome temas de Guerra, cores mais sóbrias para as roupas, com decotes que se tornaram mais ousados.

Nos anos 1920, a mulher adota a postura de heroína, aspirando independência. Usar cabelos curtos e fumar em público eram comportamentos das mulheres que se mostravam capazes de viver sem a presença dos homens. Surgem os primeiros concursos de beleza. Esses concursos permitiram que mulheres jovens entrassem no universo da moda tornando-se modelos. A liberdade, associava-se o conceito de magreza a todo custo. Nesses anos, a liberdade consistia em parecer um pouco com um homem, os seios eram achatados, os quadris eram comprimidos, as formas femininas eram martirizadas com bandagens (Faux, 2000).

Na década de 1930 o cinema passa a ditar o modelo de beleza, Greta Garbo, Marlene Dietrich e Edith Piaf, são imitadas por todas as mulheres, assumindo o arquétipo de mulheres fatais. Testa desbastada com pinça, cabelos claros, sobrancelhas reduzidas e arqueadas sobre os olhos imensos, cílios cuidadosamente recurvados, dentes do siso retirado para melhor aprofundar as bochechas, regime de emagrecimento, langor preguiçoso e voz profunda compunham o padrão de mulher fatal dos anos 1930. Os cuidados com a pele se intensificam e o olhar ganha uma atenção especial. O bronzeamento artificial se torna chique, e surgem os primeiros óculos de sombra, bem como o Pan-Cake.

Nos anos 1940 o conceito de beleza exigia uma mulher cada vez mais magra. Havia uma preocupação em formar graças ao treinamento generalizado, mulheres jovens de saúde robusta, que seriam o encanto de um lar fecundo e profícuo (Faux, 2000).

Ser bela era considerado um dever nacional. Durante o período da Segunda Guerra Mundial as estrelas de cinema adotaram cabelos longos como símbolo de feminilidade. O cinema continuou a ditar os modelos de beleza e várias atrizes salientam-se por seus dotes físicos. A sedutora submissa surgiu logo após o final da Guerra, também surgiram as picantes ou sérias e as "vamps da terra", atrizes italianas com belezas morenas, carnais, espontâneas, de coxas plenas e seios generosos, com frequência moldada em roupas pobres ou molhadas.

Para digerir a Guerra, impunha-se um apetite de doçura e a moda e a beleza se dedicariam a isso. A mulher elegante continua em alta, porém, a beleza representada pela juventude artística e intelectual passa a exprimir as idéias, o espírito e o estilo de uma nova geração.

Nos anos 1950, a arte de ser bela e de ter a pele perfeita simbolizavam a evidência e o sucesso. Inicia-se um período em que as mulheres colorem em massa seus cabelos. O rosto da época é o de uma palidez cuidadosamente criada pela maquiagem, com traços graficamente sublinhados, perpetuando a imagem de uma mulher-deusa do lar, mulher-objeto lisa e impecável. A estrela entre as estrelas da época foi Marilyn Monroe, que foi o símbolo sexual da década, trazendo, junto com a provocação ingênua, um erotismo devastador (Faux, 2000).

Na década de 1960 a beleza era representada pela silhueta adolescente, minissaia e pernas compridas, cabelos longos com franja, olhos ultra maquiados. Surgem os corantes sintéticos. As maquiagens eram duradouras e seguiam o estilo "pop". A juventude assumiu o seu lugar definitivamente na moda. $\mathrm{O}$ visual natural, a sublimação da beleza era o ápice. Em suma, nos anos 60 ocorreu uma tomada de consciência da juventude. No final dessa época surgem as modas hippie e as maquiagens psicodélicas de cores vivas.

Nos anos 1970 os cabelos tornam-se o símbolo da década. Surgem os primeiros trajes de banho com os seios à mostra, o monoquíni. As dietas de emagrecimento e os exercícios de musculação aparecem como a certeza de que o corpo deva receber o mesmo cuidado que o rosto recebeu até ali. A silhueta jovem é cheia de energia, vestindo pantalona que se torna o emblema 
da mulher jovem dos anos 1970. Surge o colágeno e o silicone. A cirurgia plástica se democratiza e levanta as questões acerca das células relacionadas ao rejuvenescimento. Uma "bula de beleza" permitia estabelecer o que convinha à pele de cada mulher. A beleza individual foi instituída, mas a juventude eterna, mais do que nunca, é a meta a alcançar. A exuberância daqueles anos chegaria ao fim com o aparecimento de um novo fenômeno da juventude que foi o movimento punk. "Seu estilo era extremamente visual com penteados porco-espinho, tingidos de azul, vermelho ou verde fluorescente, crânios raspados e tatuados, maquiagens espetaculares" (Faux, 2000. 192).

A mulher dos anos 1980 era vista como uma supermulher. A época do exagero se iniciava, não havendo mais lugar para a descontração, a naturalidade e os meios-tons. A beleza virou competição. O corpo devia ser perfeito. Era proibido fraquejar, o corpo deveria ser construído e a mulher "deveria sofrer" para ser bela. O modelo de beleza era de seios altos, pernas compridas, abdômen firme e pele bronzeada. Como a ginástica já não era suficiente para alcançar o corpo perfeito, descobriu-se que a beleza desejada estava, às vezes, na ponta do bisturi. A lipoaspiração virou moda, as injeções de colágeno eram aplicadas nos lábios, o nariz é retificado, as pálpebras são diminuídas, o volume dos seios aumentados, enfim, é possível construir a imagem desejada. Com o avanço das pesquisas sobre os mecanismos de envelhecimento da pele, o mercado dos produtos de cuidados da pele se tornou imenso, alcançando o público masculino.

Entendendo que beleza também se digere, as mulheres descobriram as virtudes do equilíbrio alimentar e entram no regime. A culinária emagrecedora é a mais falada. São lançados os produtos dietéticos. Aos poucos acredita-se que o que se come pode ser fonte de beleza. Surgem os complexos de vitaminas e os complementos alimentares (Faux, 2000).

No início dos anos 1990 a sociedade se encontra em mutação. A tendência de modificação dos corpos provoca escândalo. As modelos são magérrimas. A tatuagem é o novo emblema da feminilidade. A pele é decorada e enfeitada com decalques e tatuagens removíveis. O corpo torna-se um novo campo de expressão. O piercing mostra presença no nariz, na língua, no umbigo ou no supercílio.

Ao longo da década de 1990, graças à Internet conforme Faux (2000) e aos avanços da comunicação, o efeito da moda desconhece fronteiras e diferenças culturais. Cansados dos excessos dos anos 1980 e da depressão das magricelas, a moda e a beleza acertam seus ponteiros com o minimalista.

A época se interessa tanto com o bem-estar como com a aparência, aprende-se que a beleza é também uma questão de psicologia. O momento é de fazer as pazes com o corpo, descobrir a harmonia, sublimar-se ao invés de reformar-se: a beleza se converte em filosofia zen. Os spas recebem mulheres e homens que agora não têm mais medo de cuidar de si mesmos. "Na época da beleza pela Internet e dos lançamentos mundiais, as mulheres redescobrem o charme dos produtos antigos. A beleza não tem preço. O que é único vende bem" (Faux, 2000 p.216).

Os filósofos debruçam-se sobre o fenômeno da busca da juventude e falam do dever de ser jovem. Os médicos dizem que suas pacientes querem aparentar a idade que sentem ter. E todos se perguntam se o terceiro milênio será o da juventude eterna" (Faux, 2000, p. 220).

\subsection{Produzindo subjetividades: do ser ao não ser bonita}

$\mathrm{O}$ trabalho me permitiu de algum modo, observar o efeito dos discursos sobre juvenescimento que passa a constituir meninos e meninas de cinco anos de idade de uma classe social alta, permitindo ainda perceber o que afirma Dornelles (2002) é desse discurso que emerge o "grande espetáculo da vida" que é para alguns um modo de mostrar e ter um corpo.

Quando direcionamos o olhar para a evolução dos conceitos de beleza ao longo da história das sociedades, pode-se perceber que o efeito dos ditos sobre o que é ser bela, o que é ter o corpo "perfeito" sofre modificações e ao mesmo tempo se assemelha ao longo das décadas. Observa-se como estes ditos que acompanham principalmente a história das mulheres possibilitam "uma determinada relação consigo, e que esta relação se ancora na verdade do seu ser, no domínio e governo de 
si, nas suas transformações" Dornelles (2002, p. 156). O que nos faz pensar sobre qual o efeito disso na constituição do ser menino e do ser menina. Porque eles podem dizer: Tu és muito velha, não podes trabalhar com criança!

A análise possibilitou pensar sobre o efeito dos diferentes modos de ser bela e sobre os conceitos de beleza nas relações entre os alunos/professores desta turma que surgem como referenciais às abordagens que tratam da teoria Foucaultiana, ou mesmo da teoria feminista e pós-estruturalista, que mostram que as identidades, sejam elas sexuais, de gênero, geração, raça, religião, etnia, etc., não são fixas, resultam de negociações e construções que vão se constituindo no decorrer da vida. Estas estão em constante construção, não são um produto acabado, senão um processo contínuo que nunca se completa, subjetivando-se em seu espaço-tempo. Ou seja, "os sujeitos são constituídos no interior de jogos de poder e estão implicados nas operações de inclusão e exclusão" (Dornelles, 2002, p. 97).

As narrativas das crianças desta turma evidenciam o quanto têm sido marcante para este grupo os conceitos ligados a um tipo de beleza e de imagem corporal. Levando-se em conta que é através do corpo que nos tornamos visíveis e através dele que somos reconhecidos pelo outro, essas crianças naturalizaram esses conceitos através das relações e negociações com a cultura em que estão inseridas, em especial pela influência midiática (Campos \& Souza, 2003). Demonstram, que para elas é fundamental que os profissionais que atuam junto a elas, apresentem corpos que se enquadrem nos padrões de beleza e juventude apresentadas em seu meio social, bem como, aqueles apresentados pela mídia como os sujeitos ideais para atuarem junto às crianças.

Estas crianças se constituem através da existência direta de uma relação entre beleza e juventude, beleza e capacidade, beleza e eficiência, beleza e competência, relação essa que dita o perfil que o profissional de educação deve ter para obter sucesso na atuação com alunos da educação infantil.

Ao fragmentarmos o tempo vivido, criamos divisões arbitrárias e significamos identidades geracionais: infância, juventude, fase adulta e velhice. Na sociedade ocidental, a identidade do adulto-jovem tende a se fixar como "a legítima", "a certa", como a fase ideal e mais positiva da vida. Busco apoio em Ramos (2006), quando afirma que a fase adulta, em especial quando se aproxima da velhice, tende a ocupar o lugar de quem "deve" alguma coisa à juventude.

Sabe-se que uma das maiores conquistas da humanidade foi o aumento dos anos de vida, além de uma melhoria na saúde da população idosa, mesmo que essas conquistas não estejam nem mesmo próximas do ideal. Chegar à velhice, que antigamente era privilégio de poucas pessoas, hoje é comum, mesmo em países subdesenvolvidos. Porém, esta conquista se transformou em um dos grandes desafios para o século XXI (Dardengo \& Mafra, 2018, p. 2).

O lugar da juventude carrega consigo toda uma carga de poder que o naturaliza como o corpo aceitável, bonito, "o melhor" e isso pode ser constatado quando observamos as imagens de artistas de televisão, cinema ou revistas que apresentam como bonitas as mulheres juvenecidas e tidas como "meninas". São elas que estão autorizadas a falar de corpos, de beleza, de vida, pois são consideradas "modelos de perfeição". É portanto, "natural" apareceram na mídia imagens do corpo magro, esbelto, da mulher jovem e branca, que jamais envelhece, apesar da idade física, como o único modelo historicamente divulgado nos meios de comunicação.

Dessa forma, para esta turma em especial, o referencial de professora parece ser: jovem, loura, magra, bonita, como reafirmam a todo o momento. As professoras que não se enquadram nos padrões aceitos pelo grupo, naturalmente são excluídas e ou rejeitadas. O que nos faz pensar que a infância vai se constituindo ao longo dos tempos, permanentemente através dos múltiplos investimentos simbólicos que fazemos sobre ela, também se constitui através dos discursos que a vinculam como ingênua, pura, frágil, ou como autônoma, inconsolável e intempestiva. As infâncias se multiplicam e como diz Dornelles (2005) nos escapam. 
Faz-nos pensar também, na máquina produtiva de desejos, no império da beleza que é narrada através de discursos que advém da família, da escola, da mídia, da religião, ou seja, de todos os espectros da sociedade. Afirmo, no entanto, que cada criança é única de acordo com suas características sociais, familiares, culturais e econômicas. Contudo, não posso esquecer que cada singularidade é educada, de algum modo, para a produção do corpo homogeneizado, que é o corpo jovem, magro, sarado, esculpido, nem que seja a força de tecnologias, como modelo do corpo perfeito.

A infância das crianças às quais me refiro neste trabalho constitui-se principalmente em bairro nobre de nossa cidade. Todas moram em apartamentos com amplas dependências, juntamente com seus pais e irmãos, frequentam clubes e shoppings, possuem empregadas e babás. Têm acesso a todas as modalidades de divertimentos, atividades físicas, brinquedos e informações. Suas famílias demonstram preocupação com o juvenescimento, pois a maioria das mães e avós freqüentam academias de ginástica e já se submeteram a cirurgias plásticas, fazem dieta alimentar, implantaram silicone nos seios e nádegas, botox no rosto, fizeram lipoescultura, etc.

O que acima escrevo me remete a Hobsbawn (apud Dornelles, 2002) quando afirma que o século XX é o século do juvenescimento da sociedade, onde o espetáculo da vida é comandado por corpos cada vez mais jovens. Esses corpos não podem evidenciar as marcas do tempo e da idade. A mídia apresenta o corpo juvenescido como ideal. Cada vez mais cedo, as meninas são subjetivadas a cuidar e regular seus corpos.

As meninas desta turma estão educadas na ideia de busca de um corpo jovem e perfeito, pois aos seis anos já fazem dieta, preocupam-se com a barriguinha, deixando de comer balas e doces para não ganhar peso. Preocupam-se com suas roupas e acessórios só usando sandálias e tamancos de salto, roupas na moda, maquiagem e perfume. Busco novamente apoio em Dornelles $(2002$, ) quando diz que:

Produz-se uma auto-vigilância, um auto-controle, um auto-governo das meninas pequenas sobre seus próprios corpos [...] As meninas estão aprendendo desde muito cedo as lições sobre o seu corpo e as formas de modelá-lo para se fazerem bonitas (Dornelles, 2002, p. 106).

Contudo para os meninos o modo de ser belo está marcado pela agilidade, força e destreza e com isto chamar a atenção das meninas, porém fazem questão de evidenciar sua preferência pelas meninas que demonstram cuidado com seus corpos, e que sejam loiras, característica da colonização européia no sul do país. Europeização do modelo de beleza. Costumam aceitar em suas brincadeiras somente as meninas "bonitas", rejeitando as que não se preocupam com o vestuário ou com suas formas. Costumam falar que determinada menina é feia e fedorenta, argumentando que seu cabelo é feio porque é preto, enquanto as outras são bonitas e cheirosas e seus cabelos são bonitos por serem loiros.

Uma prática bastante comum nesta turma é que na hora do pátio um menino convide uma ou outra menina, considerada bonita, para "ficar" e "beijar". Quando questionado sobre o que estão fazendo, ele responde que só estão brincando de família. Da mesma forma classificam as professoras e assistentes como gostosas ou feias. Dizendo que esta ou aquela professora é velha e feia porque têm o "bumbum" grande ou caído, pernas finas ou grossas demais, cabelos brancos, pretos ou curtos. Daí porquê, meus alunos constantemente me perguntarem se vou pintar os cabelos, pintar as unhas, colocar batom. Dizem que meus cabelos não podem ficar brancos, pois "cabelo branco é cabelo de bisavó". "Suas avós não têm cabelos brancos, e profe é proibida de ter cabelos brancos".

Observo que as exigências com o cuidado com o aspecto físico das professoras também acompanham a história da sociedade e da educação. Esse cuidado caracteriza um governo de corpos. Me apoio em Évrard-Fiquemont no discorrer deste parágrafo (Évrard-Fiquemont apud Souza, 2000). Observo que, como diz Felipe (2004 apud Ramos 2006), com a afirmação do padrão externo de comportamento e de aparência física seriam reveladas as características pessoais, bem como os gostos, 
atitudes e marcas de identidade inscritas nos corpos das professoras. Dessa forma, posso concluir que através do governo dos corpos as personalidades, e subjetividade dos profissionais ligados à educação são intensivamente governadas.

Segundo Ramos (2006), na busca incessante por beleza e longevidade, aguardamos ansiosos pelo momento em que a velhice será eternamente adiada, isso porque, o corpo jovem e desejado é o objeto de desejo da cultura ocidental, tão fortemente marcado na cultura brasileira. Cabelos brancos, pele flácida e enrugada vem reafirmar que a norma é ser jovem, que em nossa cultura beleza e juventude são sinônimos. O corpo fica cada vez mais aprisionado a um tipo de normatividade que constitui o know-how cultural que é planetário e no qual se incluem meninas e meninos que devem desejar ser sensuais, inocentes e eróticos, jovens, fortes e naturalmente belos. Observo que em muitas ocasiões as crianças desta turma brincam desfilando ou imitando modelos e artistas e após o final da brincadeira dizem: "Estou imitando a profe do Maternal. Ela se acha!".

Com este comentário todos riem e passam a imitar os trejeitos de outra profe.

Questiono-me, se desde a infância as crianças controlam e regulam seus corpos, classificando-os como bonito ou feio, ou criticam a forma de ser das professoras da escola, ou principalmente, quando o assunto é velhice, o disciplinamento parece ficar ainda mais intenso. Contudo, quando se é jovem, ter um corpo que não se enquadra aos padrões de beleza vigente é até tolerável; entretanto quando se trata da velhice, as regras relacionadas às mudanças fisiológicas que se apresentam com a idade são quebradas, e com tantas diferenças em relação ao que é aceito como normal, com o império da beleza emergente, torna-se praticamente impossível que esse corpo seja considerado bonito. Ainda com relação a minha turma, num momento de roda de conversa, uma aluna confidenciou que detesta sua bisavó, pois ela é enrugada e feia e fica pedindo beijo, segundo a menina, isso é nojento. Quando perguntei a aluna porque considerava nojento beijar a bisavó, ela respondeu: "Aquela boca enrugada é muito nojenta, só gosto de beijo de quem é jovem!".

Para tentar dar conta do dito desta criança me apoio em Ramos (2006), quando em sua dissertação de mestrado nos mostra que as relações entre avós e netos nem sempre são afetuosas, em alguns casos ocorre o inverso, pois apesar da proximidade física, afetivamente pode existir um distanciamento. Essas relações caracterizam desconforto e não são prazerosas para a criança.

Ao comparar a professora com uma avó, as crianças explicitam que a professora comparada não se enquadra nos conceitos de beleza proclamados por nossa cultura, evidenciando o que as crianças deste grupo esperam do ser sujeito e em especial o que esperam de como deve ser o profissional da educação infantil.

De alguma maneira, as narrativas das crianças trazem à tona os modelos que a mídia, em especial à televisão, apresenta como ideais para atuar junto às crianças. Encontramos apresentadoras loiras, magras, com corpo juvenecido e "perfeito", naturalizando que a beleza e juventude trazem consigo a garantia de sucesso no contato com as crianças. O corpo juvenecido é veiculado como o ideal da força, agilidade, atividade e produtividade, características vinculadas principalmente aos adultos jovens. Dessa forma, o sujeito considerado velho passa a ser visto como alguém sem aptidão para realizar determinadas funções.

Ao questionar as crianças sobre o que representava para elas o fato de não aceitarem uma professora com idade para ser avó, elas responderam que as professoras mais velhas não deixariam que brincassem, que seriam chatas e obrigariam seus alunos a ficarem sentados. Assim se pronunciando: "Profe velha não deixa fazer nada, só quer aluno comportado, parece bruxa, tem cabelo feio, cara enrugada! Bom mesmo é profe nova, bonita, boazinha. Profe nova brinca com a gente, é amiga e legal.". De certa forma, ser velho é dar conselhos, conversar, cobrar ações e atitudes, em outras palavras ser velha é ser a bruxa má”.

Como fica esta assertiva, visto que, segundo Ramos (2007, p. 122) "nosso corpo é um campo amplo de investimentos". Ao nos representar materialmente no mundo, o corpo assume um papel fundamental nas relações geracionais 
que estabelecemos. O corpo se modifica ao longo da existência do sujeito. Ele é interpelado pela idade, doenças, condições de vida também pelas marcas sociais e culturais que atuam sobre ele". As subjetividades infantis, assim como os adultos, são produzidas por investimentos também simbólicos sobre o corpo velho. Louro (apud Dornelles 2002) afirma que:

Se pode afirmar que as subjetivações são produzidas social e culturalmente e se caracterizam por sua fluidez, instabilidade e transformações. Assim, todas as formas de subjetivação, têm seu caráter fragmentado, instável, histórico e plural. Pode-se dizer que somos sujeitos históricos porque nossos corpos ganham sentido na cultura, sociedade em que vivemos (Louro apud Dornelles, 2002, p. 151).

Ser professora, jovem e bonita nesta turma de alunos faz parte daquilo que foi inscrito nos seus corpos, a partir da cultura de cada um. Se no passado ser professora passava pelas marcas do ser sóbria, austera, solteira e se dedicar aos filhos alheios, na atualidade esse modelo parece estar cada vez mais tendo a exigência de ser uma professora com um corpo jovem, esguio, malhado, erotizado e bonito.

\subsection{Afinal, questionando o poeta: juventude e beleza são fundamentais?}

Dornelles (2002) afirma que, segundo Foucault, nos equivocamos ao pensar que, em nossa sociedade capitalista e burguesa, a realidade do corpo seja negada em detrimento da alma e da consciência. Existe um vínculo simbólico entre o profissional e sua função. Esses vínculos estão neste trabalho com crianças, diretamente ligado ao corpo.

A mídia - seja ela um vídeo, um desenho animado, uma publicidade, um capítulo de telenovela [...] é um produto que, de alguma forma, se faz "educativo", se faz "didático", pois ensina formas de ser e estar no mundo... Ao lado da informação, do divertimento, das horas de lazer oferecidas pelos produtos midiáticos, há também a formação dos sujeitos sociais. (Fischer, 1997 apud Ramos, 2006, p. 202).

Não gostaria de conduzir o desfecho deste Trabalho de Conclusão de Curso sem antes tratar daquilo a que se refere Foucault (1995, p. 263) como "ética da existência", ou seja, a "ética que determina a maneira pela qual o indivíduo deve se constituir a si mesmo como sujeito moral de suas próprias ações". Daí perguntar: como meus alunos estabelecem certas relações com determinadas regras e se reconhecem "como ligado à obrigação de pô-las em prática?" Como por exemplo não reconhecer a capacidade de um professor por ele ser negro. Como a escola pode colaborar para a produção de uma outra ética para este grupo para que possam construir sua própria ética, para sua relação com o outro sem submissão?

[...] reconhecer o preconceito etário como um problema é o primeiro passo para eliminá-lo. O próximo consiste em escolher um método para combatê-lo e conscientizar os indivíduos a respeito das suas consequências. Uma herança duradoura das relações familiares, no contexto de vidas cada vez mais longas, emerge como parte importante desse processo. Nesse sentido, sugerimos que algumas das áreas necessitadas de uma compreensão mais profunda seriam: a dos novos arranjos e vínculos permitidos pela longevidade e pelas maiores probabilidades de convivências, de como o conhecimento é transmitido entre as gerações e dentro delas; do papel da biologia, ou seja, das interações entre gene e meio ambiente, e das relações entre biologia e cultura; e do estudo das mudanças ocorridas entre e dentro das gerações, em termos de acesso aos recursos culturais e materiais. Finalmente, advogamos a necessidade de se pensar em uma legislação que elimine a discriminação por idade em diferentes setores e não apenas no emprego, tal como foi proposto recentemente na União Europeia (Goldani, 2010, p. 428).

As crianças desta turma caíram na armadilha do poder que dita formas de se ter e ser um corpo, daí questionar sobre a discriminação e o preconceito a partir dos ditos de Foucault (2002) quando analisa a sociedade e suas formas de racismo, e afirma: 
O racismo que nasce na psiquiatria dessa época [clássica] é o racismo contra o anormal, é o racismo contra os indivíduos, que, sendo portadores seja de um estado, seja de um estigma, seja de um defeito qualquer, podem transmitir a seus herdeiros, da maneira mais aleatória, as consequências imprevisíveis do mal que trazem em si. (Foucault, 2002, p. 403).

Foucault nos faz pensar no quanto ainda persistem os dogmas racistas e preconceituosos das crianças estudadas que afetam os profissionais que, por serem mais velhos, ou pertencerem aos grupos considerados diferentes (negros, gordos, etc.) trazem como afirma o autor, o mal em si. São diferenças que constituem a identidade e a diferença, assunto que nós professores não nos questionamos. Se nossos alunos são afetados pelo discurso de verdade sobre um modo de se ter um tipo de corpo hoje ou mesmo em relação à idade de suas professoras, é porque não as temos instigado a se perguntarem como o juvenescimento se tornou para ele o belo? Termino esta reflexão novamente me apoiando em Foucault (apud Dornelles, 2002, p. 157) quando nos ensina que, "o ponto mais intenso das vidas, aquele onde a sua energia se concentra, é sem dúvida aquele em que elas esbarram com o poder, se debatem com ele, se esforçam por utilizar as suas forças ou escapar às suas armadilhas”. Como se pode agir para que as crianças escapem dessa armadilha? Essa sociedade adota como meio de defesa interna contra os anormais o neorracismo.

\section{Considerações Finais}

Existem coisas que podem mudar em nossa prática junto aos alunos a fim de que ocorra um aprimoramento em nosso trabalho como educadores. Somos profissionais em constante construção. Planejamos, preparamos, avaliamos e nos autoavaliamos constantemente. Cursos, seminários, grupos de formação e leituras fazem parte de nossa rotina em busca de uma especialização na área em que atuamos.

Durante muito tempo acreditamos que saber e gostar do que se faz era suficiente para sermos eficientes em nossa profissão. Contudo dependendo do espaço em que atuamos isto parece não ser o suficiente. Ser uma profissional séria, competente, comprometida com a educação das crianças nesta escola, ou especialmente para este grupo, isto não basta para que se seja aceita e valorizada.

Ao refletir sobre um tema que se faz presente em nosso cotidiano e mexe com nossas emoções e sentimentos, muitos questionamentos vão surgindo. Entendo que o efeito dos discursos utilizados por meus alunos é constantemente influenciado pelos discursos midiáticos, pois, em muitos momentos as crianças se referem às personagens das novelas da Rede Globo como modelos de beleza e juventude. Em certa ocasião, um menino confidenciou: "Sonhei que a Bebel era minha professora. A Bebel é muito linda!'”.

Este trabalho possibilitou a reflexão acerca da evidência do efeito do império da beleza neste grupo de alunos da Educação Infantil, especificamente no Jardim II. Como continuidade da pesquisa, estipulamos a necessidade de desconstruir esses sentimentos antagonistas, contribuindo para o desenvolvimento da tolerância, respeito ao próximo, cidadania e igualdade.

\section{Referências}

Campos, C. C. G., \& Souza, S. J. (2003). Mídia, cultura do consumo e constituição da subjetividade na infância. Psicologia: Ciência e Profissão, 23(1), 1221. https://doi.org/10.1590/S1414-98932003000100003.

Carvalho, T. A. P. (2020). Geropedagogia: educar para envelhecer. Atena.

Castro, G. G. S. (2016). O idadismo como viés cultural: refletindo sobre a produção de sentidos para a velhice em nossos dias. Galáxia, (31), 79-91. https://doi.org/10.1590/1982-25542016120675.

Dardengo, C. F. R., \& Mafra, S. C. T. (2018). Os Conceitos de Velhice e Envelhecimento ao longo do tempo: contradição ou adaptação? Revista de Ciências Humanas, 18(2). https://periodicos.ufv.br/RCH/article/view/8923/pdf_1.

Dornelles, L. V. (2002). Meninas no papel. Tese (Doutorado em Educação) - Universidade Federal do Rio Grande do Sul. Faculdade de Educação, Porto Alegre/RS. 176f. 
Research, Society and Development, v. 10, n. 14, e463101422625, 2021

(CC BY 4.0) | ISSN 2525-3409 | DOI: http://dx.doi.org/10.33448/rsd-v10i14.22625

Dornelles, L. V. (2005). Infâncias que nos escapam: da criança na rua à criança cyber. Vozes.

Dornelles, L. V. (Org.). (2007). Produzindo pedagogias interculturais na infância. Vozes.

Faux, D. S. (2000). Beleza do Século. Cosac e Naify Edições.

Foucault, M. (1995). Sobre a genealogia da ética: uma revisão do trabalho. In: Dreifus, P., \& Rabinow, H. (Org.). Uma trajetória filosófica: para além do estruturalismo e da hermenêutica. Forense.

Foucault, M. (2001). Os anormais: curso no Collège de France (1974-1975). Martins Fontes.

Fischer, R. M. B. (1994). O capricho das disciplinas. Educação e Realidade, 19(2), 47-66. https://seer.ufrgs.br/educacaoerealidade/issue/viewIssue/3048/317.

Goldani, A. M. (2010). Desafios do "Preconceito Etário" no Brasil. Educação e Sociedade, 31(111), 411-434. https://doi.org/10.1590/S010173302010000200007.

Guerra, L., Fanfa, M. S., Tolentino Neto, L. C. B., \& Shetinger M. R. C. (2020). Animais Peçonhentos: concepções prévias de alunos de uma Escola Rural. Revista Areté - Revista Amazônica de Ensino de Ciências, 14(28), 45-56. http://periodicos.uea.edu.br/index.php/arete/article/view/1983.

Martins, H. H. T. S. (2004). Metodologia qualitativa de pesquisa. Educação e Pesquisa, 30(2), 284-300. https://doi.org/10.1590/S1517-97022004000200007.

Moraes, M. C. (2000). O Paradigma Educacional Emergente. Papirus.

Pereira, A. S., Shitsuka, D. M., Parreira, F. J., \& Shitsuka, R. (2018). Metodologia da Pesquisa Científica. UFSM.

Ramos, A. C. (2006). Cultura Infantil e envelhecimento: o que as crianças têm a dizer sobre a velhice? um estudo com meninos e meninas da periferia de Porto Alegre. UFRGS.

Souza, J. F. (2000). Governando mulheres e crianças: Jardins de infância em Porto Alegre na primeira metade do século XX. Tese (Doutorado em Educação) - Universidade Federal do Rio Grande do Sul. 201f.

Severino, A. J. (2013). Metodologia do trabalho científico. Cortez.

Wendling, C. M., \& Campos, S. D. (2003). Análise de Registros em Diário de Bordo sobre Alfabetização. Anais do lll Seminário regional de formação continuada de professores, lll mostra de Experiências e vivências pedagógicas. Presidente Prudente: Universidade Estadual do Oeste do Paraná, PR. https://www.redalyc.org/articulo.oa?id=445944368008. 